\title{
Risk Factors of Caregiver Burden Among Patients with Alzheimer's Disease or Related Disorders: A Cross-Sectional Study
}

\author{
Virginie Dauphinot ${ }^{\mathrm{a}, *}$, Floriane Delphin-Combe ${ }^{\mathrm{a}}$ Christelle Mouchoux $^{\mathrm{b}, \mathrm{c}, \mathrm{d}}$, Aline Dorey ${ }^{\mathrm{a}}$, \\ Anthony Bathsavanis ${ }^{\mathrm{a}}$, Zaza Makaroff ${ }^{\mathrm{a}}$, Isabelle Rouch ${ }^{\mathrm{a}, \mathrm{e}}$ and Pierre Krolak-Salmon ${ }^{\mathrm{a}, \mathrm{b}, \mathrm{d}}$ \\ ${ }^{a}$ Memory Research Centre of Lyon (CMRR); Geriatrics Unit, Charpennes Hospital, University Hospital of Lyon, \\ Villeurbanne, France \\ ${ }^{\mathrm{b}}$ Research Clinic Centre (CRC) - VCF (Aging - Brain - Frailty), Charpennes Hospital, University Hospital of Lyon, \\ Villeurbanne, France \\ ${ }^{\mathrm{c}}$ University Hospital of Lyon, Pharmaceutical Unit, Lyon, France \\ ${ }^{\mathrm{d}}$ University Lyon 1, INSERM, U1028, UMR CNRS 5292, Research Centre of Neurosciences of Lyon, Lyon, France \\ ${ }^{\mathrm{e}}$ Neurology Unit, University Hospital of Saint-Etienne, Saint Etienne, France
}

Accepted 29 September 2014

\begin{abstract}
.
Background: Caregivers play a major role in the care of patients with dementia and are themselves at higher risk of disease. Objectives: We investigate which factors are associated with caregivers burden of outpatients visiting a memory clinic and how functional autonomy and behavioral and psychological symptoms can influence caregiver burden.

Methods: The study population was chosen from outpatients with progressive cognitive complaint. The caregiver burden was measured with the short version of the Zarit Burden Interview (ZBI). The relationship was assessed between the ZBI and the patients characteristics, including Neuropsychiatric Inventory (NPI), Instrumental Activities of Daily Living scale (IADL), the Mini-Mental State Examination (MMSE), etiology, and stage of the cognitive impairment.

Results: In a population of 548 patients, IADL, NPI, antidepressant drugs, and MMSE were found to be related to ZBI, while diagnosed etiology and disease stage were not significant: ZBI decreased by 0.34 point for every unit of IADL, and by 0.03 point for every unit of MMSE; ZBI increased by 0.03 point for every unit of NPI. From the IADL scale, the ability to handle finances, food preparation, responsibility to take medications, mode of transportation, and ability to use the telephone increased the ZBI. Five areas of the NPI increased the ZBI: apathy, agitation, aberrant motor behavior, appetite disorders $(p<0.001)$, and irritability $(p=0.03)$.

Conclusion: Caregivers experience a higher burden due to disease symptoms such as impairment of functional autonomy and behavioral and cognitive impairment, whatever the etiology of the cognitive decline.
\end{abstract}

Keywords: Alzheimer's disease or related disorder, behavioral disorders, caregiver, dementia, dependency, elderly

\section{INTRODUCTION}

Informal caregivers have a major role in the care and home support of patients with Alzheimer's disease

\footnotetext{
*Correspondence to: Virginie Dauphinot, Hôpital des Charpennes, 27 rue Gabriel Péri, 69100 Villeurbanne, France. Tel.: +330 472433114; Fax: +33 0 472432054; E-mail: virginie. dauphinot@chu-lyon.fr.
}

(AD) and related disorders, responsible for a progressive impairment of cognitive and functional performance as well as behavioral disorders [1, 2]. However, caregivers, often referred as the "hidden patient", are known to have a higher risk of anxiety, depressive and sleep disorders, reduced quality of life, a higher risk of cardiovascular morbidity and mortality [3-9]. Strategies have been developed to change potentially 
modifiable risk factors in order to reduce the burden of the caregiver, and to delay patient admission into nursing homes, which ultimately benefits both patients and caregivers [10-12]. The success of any action should be based on the knowledge of the different risk factors of the burden of primary caregivers. The caregiver burden, assessed with the Zarit Burden Interview (ZBI), has been found to be related to patients symptoms, such as behavioral and psychological symptoms, cognitive performance and functional autonomy, as well as with their personal characteristics such as gender educational level [3, 13-16]. Nevertheless, discrepancies have appeared among the previous studies, probably due to differences in the etiologies and degree of severity of disease of the different study populations and also to the various methods of burden assessment. In addition, no previous study has been carried out to evaluate risk factors of caregiver burden, assessed with the short version of the $\mathrm{ZBI}$, oriented toward routine medical care [17].

The aim of this study was to investigate the risk factors of the increased burden perceived by caregivers taking in charge patients visiting a memory clinic, in terms of diagnosed etiology and disease stage, symptoms of the disease as well as pharmacological and non-pharmacological therapies. In addition, we assessed which areas were associated with higher caregiver burden: functional autonomy on the one hand, and behavioral and psychological symptoms on the other hand.

\section{MATERIALS AND METHODS}

\section{Study design and setting}

This study had a cross-sectional design. Data was extracted from a patient's medical record database, which aims to follow a patients' cohort, at the Clinical and Research Memory Centre of Lyon (Charpennes Hospital, University Hospital of Lyon, France).

\section{Study population}

The study population included a sample of consecutive outpatients having undergone a medical examination with a neurologist or a geriatrician, between the 1 November 2011 and the 31 December 2013.

The inclusion criteria were a cognitive complaint, either expressed by the patient or one of their relatives, at any stage of disease (Subjective cognitive complaint (SCC), mild cognitive impairment (MCI), or dementia). Written information regarding the collection of individual data was provided to the patients and caregivers. Authorization for handling personal data has been granted by the French Data Protection Authority (CNIL: Commission Nationale de l'Informatique et Libertês): 06/08/2010, number of registration: 10-18.

\section{Caregiver variables}

The subjective caregivers burden was assessed using the validated short version of the Zarit Burden Inventory, which was previously developed for routine medical care $[16,17]$. The score was noted as a continuous variable ranging from 0 (no burden) to 7 (higher burden). The questionnaire included seven questions for which the caregivers could answer "never", "sometimes" or "nearly always": Does the fact of caring for your relative lead to 1) Difficulties in your family life; 2) Difficulties in your relationship with friends, hobbies, or in your work; 3) An impact on your health; 4) Do you have the feeling of no longer recognizing your relative?; 5) Are you concerned for the future of your relative?; 6) Do you feel you need more help to take care of your relative?; 7) Do you feel a burden in taking care of your relative?

The answers were first self-reported by the primary caregiver in a questionnaire sent to their home before the patient's consultation at the memory center. At the beginning of the memory consultation, the questionnaires were verified and checked by a trained nurse in a personal interview with the caregiver. Answers were reported in the eCRF collecting together all the patient data, using the software Cristalnet ${ }^{\circledR}$, developed by the Centre Régional Informatique Hospitalière (CRIH) des Alpes and the computer and software service of the University Hospital of Grenoble (France).

The relationship between the caregivers and their patients was recorded as (1) spouse, (2) child, stepchild, or grandchild, (3) brother, sister, niece or nephew, or (4) other unspecified caregiver.

\section{Patients' characteristics and medical data}

Socio demographic characteristics were collected in the eCRF during the memory consultation: gender, date of birth, marital status, educational level, address location, and current living situation, i.e., living at home with its husband/spouse, at home with relatives, alone at home with relatives in the neighborhood, alone at home without relatives in the neighborhood, or unspecified other living situation.

The behavioral and psychological symptoms of dementia (BPSD) were assessed using the 
Neuropsychiatric Inventory (NPI) at the memory consultation [18]. This scale evaluates ten behavioral domains including delusions, hallucinations, agitation/aggression, depression/dysphoria, anxiety, elation/euphoria, apathy/indifference, disinhibition, irratibility/lability, aberrant motor behavior, sleep/nighttime behavioral disorders, and appetite/eating disorders. A higher overall NPI score (maximum 144) indicates more severe behavioral disorders.

Functional autonomy level was assessed with the Instrumental Activities of Daily Living scale (IADL) during the interview with the primary caregiver combined with the memory consultation. The IADL assessed 8 instrumental activities: ability to use the telephone, shopping, food preparation, housekeeping, laundry, mode of transportation, responsibility for own medications, and ability to handle finances, the score ranging from 0 (dependent) to 8 (independent) $[11,19]$.

Overall cognitive performance was assessed with the Mini-Mental State Examination (MMSE) [20]. The disease stage was established on the basis of the McKhann and the Albert criteria, respectively for dementia and MCI [21, 22]. The etiologies were identified as follows: $\mathrm{AD}, \mathrm{AD}$ with cerebrovascular component, vascular dementia (NINDS-AIREN criteria), Lewy body disease, frontotemporal dementia, other pathologies leading to a progressive cognitive impairment (including chronic hydrocephalus, progressive supranuclear palsy, corticobasal degeneration, and unclassified dementia), Parkinson's disease, psychiatric disorders (including psychoses, anxious disorder, isolated depression disorder, recurrent depressive disorder, bipolar disorder and unclassified psychiatric disorders) and others disorders (including other neurological diseases such as tumor and aneurysm, head injury, and organic brain disorder related to the pathology such as metabolic deficiency) [21-25].

Non-pharmacological therapies included home services, such as nurse care, day care units, speech therapy, physical therapy, psychological support, cognitive rehabilitation, or other non-pharmacological treatments. No distinction was made in the analysis for different types of non-pharmacological approaches. Recorded data of pharmacological therapies focused on nervous system drugs such as cholinesterase inhibitors and memantine (ATC-anatomical, therapeutically, chemical code starting by N06D: donepezil, rivastigmine or galantamine), antipsychotics drug use (ATC code starting by N05A), anxiolitics drug use (ATC code starting by N05B), antidepressants drug use (ATC code starting by N06A), hypnotic and sedative drugs use (ATC code starting by N05C)
(Methodology: http://www.whocc.no/atc_ddd_index/). Due to infrequent use of nootropes $(1.2 \%)$, these drugs were not taken into account in this study.

\section{Statistical analysis}

The study population characteristics were reported using the mean value \pm standard deviation (SD) or the frequency (percentage) depending of the nature of the data. The mean value of the short version of the ZBI was presented using these characteristics. Pearson's correlations between covariates were calculated. Unadjusted linear regression analyses were performed to investigate the relationship between each characteristic, considered as possible risk factors, and the short version of the ZBI. The sample size was considered to be sufficiently large to allow the use of linear regression. In the absence of significant interaction with gender, stage of the disease, and etiologies in the models, analyses were not stratified. Multivariate linear regression analyses were performed using a stepwise approach and included all the characteristics that were found to be significant in the unadjusted model at the initial step. Therefore, estimates were adjusted for all the significant characteristics which remained significant at the final step. The R-squared $\left(\mathrm{R}^{2}\right)$ coefficients of determination were calculated at each step of the step-wise multivariate regression. Results are summarized by crude and adjusted regression coefficients with their $95 \%$ confidence intervals $(95 \% \mathrm{CI})$, and the significance of the coefficients in the equations ( $p$ values). Further analysis was performed to determine which domains of IADL and NPI contributed significantly to ZBI. Statistical tests were two-tailed and $p$ values below 0.05 were considered to be statistically significant. Analyses were performed using SPSS (Statistical Package for the Social Sciences) version 17.0 for Windows (SPSS Inc., Chicago, Illinois, USA).

\section{RESULTS}

A total of 548 patients $(61.7 \%$ female, mean age: $81.1 \pm 7$ ) were included in the study (Table 1). The overall mean of the short version of the ZBI was $3.6 \pm 2$. The majority of caregivers were spouses $(44 \%)$ or children/stepchildren/grandchildren (44\%). In the unadjusted models, the ZBI was negatively associated $(p<0.001)$ with MMSE and IADL, and positively associated with NPI $(p<0.001)$. The mean ZBI increased steadily as the disease stage increased: the ZBI was higher for patients with dementia compared 
Table 1

Characteristics of patients, association with short version of the Zarit Burden Interview (ZBI) caregivers and crude means of Zarit burden Interview according to patients' characteristics $(n=548)$

\begin{tabular}{|c|c|c|c|c|}
\hline Variables & $\begin{array}{l}\text { Mean } \pm \text { SD or } \\
\text { Frequency }(\%)\end{array}$ & $\begin{array}{l}\text { Crude mean } \\
\text { Short } \mathrm{ZBI} \pm \mathrm{SD}\end{array}$ & $\begin{array}{c}\text { Univariate linear } \\
\text { regression coefficient } \\
\text { B }(95 \% \mathrm{CI})\end{array}$ & $p$ value \\
\hline Age (in years) & $81.10 \pm 7.21$ & - & $0.02(-0.01,0.04)$ & 0.18 \\
\hline \multicolumn{5}{|l|}{ Gender } \\
\hline Male & $210(38.32 \%)$ & $3.86 \pm 2.04$ & - & - \\
\hline Female & $338(61.68 \%)$ & $3.37 \pm 1.94$ & $-0.50(-0.84,-0.15)$ & 0.005 \\
\hline \multicolumn{5}{|l|}{ Marital Status } \\
\hline Married / in couple & $284(51.82 \%)$ & $3.53 \pm 2.04$ & - & - \\
\hline Widowed & $160(29.20 \%)$ & $3.59 \pm 1.92$ & $0.07(-0.32,0.45)$ & 0.73 \\
\hline Divorced/ separated & $29(5.29 \%)$ & $3.52 \pm 1.92$ & $-0.01(-0.77,0.75)$ & 0.98 \\
\hline Single & $18(3.28 \%)$ & $2.89 \pm 1.92$ & $-0.64(-1.59,0.31)$ & 0.19 \\
\hline Unspecified & $57(10.40 \%)$ & $3.83 \pm 2.01$ & $0.31(-0.26,0.88)$ & 0.29 \\
\hline \multicolumn{5}{|l|}{ Educational level } \\
\hline Primary & $210(38.32 \%)$ & $3.40 \pm 1.99$ & - & - \\
\hline Secondary & $173(31.57 \%)$ & $3.60 \pm 2.08$ & $0.21(-0.19,0.61)$ & 0.31 \\
\hline Tertiary & $73(13.32 \%)$ & $3.64 \pm 2.00$ & $0.25(-0.28,0.78)$ & 0.36 \\
\hline Nil & $92(16.79 \%)$ & $3.77 \pm 1.82$ & $0.37(-0.12,0.86)$ & 0.14 \\
\hline \multicolumn{5}{|l|}{$\begin{array}{l}\text { Geographical location with } \\
\text { regard to the memory clinic }\end{array}$} \\
\hline City of the memory clinic & $468(85.40 \%)$ & $3.61 \pm 1.99$ & - & - \\
\hline Outside the city & $80(14.60 \%)$ & $3.23 \pm 2.00$ & $-0.38(-0.85,0.09)$ & 0.11 \\
\hline \multicolumn{5}{|l|}{ Current living situation } \\
\hline At home with its husband/spouse & $313(57.12 \%)$ & $3.55 \pm 2.05$ & - & - \\
\hline At home with relatives & $41(7.48 \%)$ & $4.16 \pm 1.87$ & $0.61(-0.04,1.25)$ & 0.07 \\
\hline $\begin{array}{l}\text { At home, alone, with relatives } \\
\text { in the neighborhood }\end{array}$ & $140(25.55 \%)$ & $3.56 \pm 1.85$ & $0.01(-0.39,0.40)$ & 0.98 \\
\hline $\begin{array}{l}\text { At home, alone, without relatives } \\
\text { in the neighborhood }\end{array}$ & $27(4.93 \%)$ & $2.74 \pm 1.99$ & $-0.81(-1.59,-0.03)$ & 0.04 \\
\hline Other lifestyle & $27(4.93 \%)$ & $3.52 \pm 1.97$ & $-0.03(-0.81,0.75)$ & 0.94 \\
\hline \multicolumn{5}{|l|}{$\begin{array}{l}\text { Relationship between the patient } \\
\text { and the primary caregiver }\end{array}$} \\
\hline Spouse & $241(43.98 \%)$ & $3.52 \pm 2.08$ & - & - \\
\hline Child, stepchild, grandchild & $240(43.80 \%)$ & $3.65 \pm 1.89$ & $0.13(-0.23,0.49)$ & 0.47 \\
\hline Brother, sister, niece, nephew & $21(3.83 \%)$ & $2.88 \pm 1.69$ & $-0.64(-1.53,0.25)$ & 0.16 \\
\hline Other unspecified caregiver & $46(8.39 \%)$ & $3.53 \pm 2.12$ & $0.01(-0.62,0.64)$ & 0.98 \\
\hline \multicolumn{5}{|l|}{ Measurements } \\
\hline Mini-Mental State Examination & $18.98 \pm 6.39$ & - & $-0.10(-0.13,-0.08)$ & $<0.001$ \\
\hline Neuropsychiatric Inventory & $21.03 \pm 17.17$ & - & $0.05(0.04,0.06)$ & $<0.001$ \\
\hline $\begin{array}{l}\text { Instrumental Activities } \\
\text { of Daily Living scale }\end{array}$ & $3.10 \pm 2.28$ & - & $-0.45(-0.51,-0.38)$ & $<0.001$ \\
\hline \multicolumn{5}{|l|}{ Diagnosis stage } \\
\hline Subjective Cognitive Complaint & $72(13.14 \%)$ & $2.51 \pm 2.15$ & - & - \\
\hline Mild Cognitive Impairment & $150(27.37 \%)$ & $3.22 \pm 1.90$ & $0.71(0.16,1.25)$ & 0.01 \\
\hline Dementia & $326(59.49 \%)$ & $3.94 \pm 1.89$ & $1.43(0.94,1.92)$ & $<0.001$ \\
\hline \multicolumn{5}{|l|}{ Diagnosis etiology } \\
\hline Alzheimer's disease & $316(57.66 \%)$ & $3.79 \pm 1.87$ & - & - \\
\hline $\begin{array}{l}\text { Alzheimer's disease with } \\
\text { cardiovascular component }\end{array}$ & $48(8.76 \%)$ & $3.50 \pm 1.99$ & $-0.29(-0.88,0.31)$ & 0.34 \\
\hline Vascular dementia & $38(6.93 \%)$ & $3.00 \pm 2.17$ & $-0.79(-1.44,-0.14)$ & 0.02 \\
\hline Lewy body disease & $16(2.92 \%)$ & $4.25 \pm 1.39$ & $0.46(-0.51,1.44)$ & 0.35 \\
\hline Frontotemporal dementia & $11(2.01 \%)$ & $4.77 \pm 1.54$ & $0.99(-0.18,2.15)$ & 0.10 \\
\hline Other dementia & $16(2.92 \%)$ & $4.41 \pm 1.85$ & $0.62(-0.36,1.59)$ & 0.21 \\
\hline Parkinson's disease & $13(2.37 \%)$ & $2.69 \pm 2.26$ & $-1.10(-2.17,-0.02)$ & 0.046 \\
\hline Psychiatric disorders & $39(7.12 \%)$ & $2.99 \pm 2.18$ & $-0.80(-1.45,-0.16)$ & 0.02 \\
\hline Others disorders & $51(9.31 \%)$ & $2.50 \pm 2.07$ & $-1.29(-1.86,-0.71)$ & $<0.001$ \\
\hline \multicolumn{5}{|l|}{ Non-pharmacological treatment } \\
\hline None & $314(57.30 \%)$ & $3.45 \pm 2.04$ & - & - \\
\hline Yes & $234(42.70 \%)$ & $3.70 \pm 1.91$ & $0.25(-0.09,0.59)$ & 0.15 \\
\hline
\end{tabular}




\begin{tabular}{|c|c|c|c|c|}
\hline \multicolumn{5}{|c|}{$\begin{array}{c}\text { Table } 1 \\
\text { Continued }\end{array}$} \\
\hline Variables & $\begin{array}{l}\text { Mean } \pm \text { SD or } \\
\text { Frequency }(\%)\end{array}$ & $\begin{array}{c}\text { Crude mean } \\
\text { Short } \mathrm{ZBI} \pm \mathrm{SD}\end{array}$ & $\begin{array}{c}\text { Univariate linear } \\
\text { regression coefficient } \\
\text { B }(95 \% \mathrm{CI})\end{array}$ & $p$ value \\
\hline \multicolumn{5}{|c|}{ Number of non-pharmacological treatment } \\
\hline None & $314(57.30 \%)$ & $3.45 \pm 2.04$ & - & - \\
\hline 1 & $138(25.18 \%)$ & $3.57 \pm 1.97$ & $0.12(-0.28,0.52)$ & 0.56 \\
\hline 2 & $60(10.95 \%)$ & $3.88 \pm 1.71$ & $0.42(-0.13,0.98)$ & 0.13 \\
\hline 3 or more & $36(6.57 \%)$ & $3.90 \pm 2.01$ & $0.45(-0.24,1.14)$ & 0.20 \\
\hline \multicolumn{5}{|c|}{ Pharmacological treatment* } \\
\hline Anti-dementia drugs & $259(47.26 \%)$ & $3.81 \pm 1.89$ & $0.47(0.14,0.80)$ & 0.006 \\
\hline Antipsychotics & $33(6.02 \%)$ & $5.06 \pm 1.50$ & $1.60(0.91,2.29)$ & $<0.001$ \\
\hline Anxiolitics & $102(18.61 \%)$ & $4.35 \pm 1.83$ & $0.97(0.55,1.39)$ & $<0.001$ \\
\hline Antidepressants & $195(35.58 \%)$ & $4.05 \pm 1.84$ & $0.77(0.43,1.12)$ & $<0.001$ \\
\hline Hypnotics or sedatives & $23(4.20 \%)$ & $3.83 \pm 1.99$ & $0.28(-0.55,1.12)$ & 0.51 \\
\hline
\end{tabular}

*reference: without respective drug use.

Table 2

Factors associated with the short version of ZBI: Multiple linear regression $(n=443)$

\begin{tabular}{|c|c|c|c|c|}
\hline Variables* & $\begin{array}{l}\text { Adjusted mean } \\
\text { Short } \mathrm{ZBI} \pm \mathrm{SD}\end{array}$ & $\begin{array}{l}\text { Multivariate linear } \\
\text { regression coefficient } \\
\text { B }(95 \% \mathrm{CI})\end{array}$ & $p$ value & $\begin{array}{c}\mathrm{R}^{2} \text { at each step of } \\
\text { inclusion of variables } \\
\text { in the model }\end{array}$ \\
\hline IADL & - & $-0.34(-0.41,-0.27)$ & $<0.001$ & $26 \%$ \\
\hline NPI & - & $0.03(0.03,0.04)$ & $<0.001$ & $34 \%$ \\
\hline Antidepressants use ${ }^{\dagger}$ & $3.90 \pm 1.84$ & $0.53(0.25,0.81)$ & $<0.001$ & $36 \%$ \\
\hline MMSE & - & $-0.03(-0.05,-0.01)$ & 0.025 & $37 \%$ \\
\hline
\end{tabular}

*Variables in order of entry in the multivariate model. ${ }^{\dagger}$ Reference category: without use of antidepressant. Variables excluded of the multivariate model: gender $(p=0.44)$, diagnosis etiology $(p=0.32)$, diagnosis stage $(p=0.25)$, anti-dementia drugs use $(p=0.33)$, antipsychotic drugs $(p=0.10)$, and anxiolotic drugs $(p=0.06)$.

to those with SCC or MCI, the ZBI being also higher for patients with MCI compared to patients with SCC. The ZBI was lower among patients with AD with cardiovascular component, Parkinson's disease, psychiatric disorders, or other disorders compared to patients with AD.

Regarding pharmacological treatment, the ZBI was significantly higher for patients on anti-dementia treatment, antipsychotics, anxiolitics, or antidepressants compared to patients without these specific treatments.

When the significant variables associated with ZBI were modelled together in the adjusted model, IADL, NPI, antidepressant drugs, and MMSE remained significant, while the stage and the etiology of the cognitive impairment as well as the other pharmacological treatment were not significant anymore (Table 2). In particular, for every additional unit of IADL, the ZBI decreased by 0.34 point, holding all other cofactors constant. For every additional unit of NPI, there was a 0.03 point increase of the ZBI, while for every additional unit of MMSE, the ZBI decreased by 0.03 point, all things being equal.

Analyses of the correlations between covariates showed that IADL, NPI, and MMSE were significantly related to each other, and were overlapping risk factors for the ZBI. In the step-wise multivariate regression, the inclusion of MMSE in the model led to the exclusion of diagnosed stage and etiology, showing that both the diagnosed stage and etiology were proxy factors for MMSE.

Of the eight domains evaluated in the IADL scale, five domains were associated significantly with the ZBI, after adjustment for all the significant domains of IADL, NPI, MMSE, and antidepressant drugs use (Table 3). The frequencies of the domains are presented in Table 3. When these are successively introduced in the models, the dependence in the ability to handle finances, food preparation, responsibility to take own medications, mode of transportation, and the ability to use the telephone significantly increased the ZBI, whereas other domains of IADL were not significant.

Of the 12 behavioral domains explored with the NPI, five areas were significantly related to ZBI (Table 4). The frequencies of these symptoms is presented in Table 4. In the order of importance, apathy/indifference, agitation/aggression, aberrant motor behavior, appetite/eating disorders, and irritability/lability significantly increased the ZBI, after adjustment for all significant areas of NPI, IADL, MMSE, and antidepressant drugs use. 
Table 3

Domains of IADL associated with the short version of ZBI

\begin{tabular}{lcccr}
\hline $\begin{array}{l}\text { Domains composing } \\
\text { IADL scale }^{\dagger}\end{array}$ & $\begin{array}{c}\text { Frequency }- \\
\text { Dependent for }(\%)\end{array}$ & $\begin{array}{c}\text { Adjusted* mean } \\
\text { Short ZBI } \pm \text { SD }\end{array}$ & $\begin{array}{c}\text { Multivariate linear regression } \\
\text { coefficient B }(95 \% \text { CI) }\end{array}$ & $p$ value \\
\hline Ability to handle finances & $379(69.7 \%)$ & $3.48 \pm 1.87$ & $0.77(0.39,1.15)$ & $<0.001$ \\
Food preparation & $296(54.2 \%)$ & $3.63 \pm 1.86$ & $0.66(0.32,1.00)$ & $<0.001$ \\
Responsibility for own medications & $420(77.2 \%)$ & $3.70 \pm 1.88$ & $0.79(0.38,1.19)$ & $<0.001$ \\
Mode of transportation & $284(52.0 \%)$ & $3.52 \pm 1.87$ & $0.44(0.11,0.77)$ & 0.009 \\
Ability to use telephone & $119(21.8 \%)$ & $3.56 \pm 1.74$ & $0.51(0.10,0.91)$ & 0.02 \\
\hline
\end{tabular}

*Means and regression coefficients (reference: independence for the respective domain), adjusted for others significant domains of IADL. ${ }^{\dagger}$ Domains of laundering $(p=0.42)$, shopping $(p=0.36)$, and housekeeping $(p=0.11)$ did not contribute to short version of ZBI.

Table 4

Domains of NPI associated with the short version of ZBI

\begin{tabular}{lccc}
\hline $\begin{array}{l}\text { Behavioral and neurovegetative } \\
\text { areas of the NPI }\end{array}$ & $\begin{array}{c}\text { Frequency }- \\
\text { Presence }(\%)\end{array}$ & $\begin{array}{c}\text { Adjusted mean } \\
\text { Short ZBI } \pm \text { SD }\end{array}$ & $\begin{array}{c}\text { Multivariate linear regression } \\
\text { coefficient B }(95 \% \text { CI)* }\end{array}$ \\
\hline Apathy/Indifference & $376(68.6 \%)$ & $4.36 \pm 1.85$ & $1.11(0.78,1.43)$ \\
Agitation/Aggression & $161(29.4 \%)$ & $4.21 \pm 1.76$ & $0.80(0.44,1.16)$ \\
Aberrant motor behavior & $178(32.5 \%)$ & $4.13 \pm 1.73$ & $0.65(0.33,0.98)$ \\
Appetite/Eating disorders & $134(24.5 \%)$ & $4.14 \pm 1.82$ & $0.67(0.32,1.01)$ \\
Irritability/lability & $264(48.2 \%)$ & $3.99 \pm 1.92$ & $0.37(0.04,0.70)$ \\
\hline
\end{tabular}

* Means and regression coefficients (reference: absence of the respective symptom), adjusted for others significant areas of NPI, MMSE, IADL and use of antidepressant drugs. ${ }^{\dagger}$ Areas of delusions $(20.3 \%)$, hallucinations $(12.0 \%)$, depression/dysphoria (44.2\%), anxiety (51.8\%), elation/euphoria (8.0\%), disinhibition (19.3\%), and sleep/nighttime behavior disorders (17.0\%) did not contribute to short version of ZBI.

\section{DISCUSSION}

This study highlights that patients' impairment in instrumental activities of daily living, behavioral and psychological disorders as well as overall cognitive severity are all concomitant risk factors of subjective caregiver burden, independently of the etiology and the stage of cognitive impairment. Indeed, the diagnosis stage and etiology played a role of proxy factors for the MMSE, meaning that cognitive impairment contributes more to the caregiver burden than the diagnosis itself in this population study, even at an early stage of the disease [26].

The originality of this study is based on the exploration of the different stages and etiologies of the cognitive impairment without stratification of the analysis according to these diagnoses. The severity of the cognitive impairment and the symptoms of the disease were the best predictive characteristics of subjective caregiver burden. Our study includes patients with a larger scale of diagnoses, i.e., AD and related diseases, and a different assessment of caregiver burden is used, more suitable for current practice (short version of ZBI versus original version of $\mathrm{ZBI}$ ). All patients visiting a memory clinic were considered in this investigation, without selecting the study population according to a diagnosis stage or an etiology in order to provide a realistic overview of the situation faced by caregivers and patients treated in memory centers. Indeed, what may be more important for a caregiver is the loss of the patient's functional capacities, which would have to be compensated for, and the behavioral and memory disorders that could change the patient's personality and strongly impact the patient/caregiver lifestyle and relationship. Previous studies have investigated risk factors for caregiver burden, either by focusing their analyses on patients with a specific dementia stage (MCI or dementia) or on a specific etiology (i.e., AD, Parkinson's disease), or either by stratifying the analyses according to different etiologies [15, 27-31]. Consequently, it may explain why different results are found in terms of the risk factors of the caregiver burden. In particular, the place of the MMSE as a risk factor of the caregiver is not found in all studies. In the Machnicki et al. study, in which analyses are stratified according to etiologies, BPSD had the most important impact in caregiver burden, functional (IADL) and cognitive (MMSE) impairment being only mildly correlated to burden for patients with MCI or dementia [32]. Even more so, in the same study, among patients with depression or cerebrovascular disease, only BPSD was related to caregiver burden, whereas functional and cognitive impairment were non-significant. In another study, Riedijk et al. highlighted that burden was higher for caregivers of patients with frontotemporal dementia than patients with AD [33]. The discrepancy observed among previous studies may be related to the heterogeneity of the study populations. According to previous 
work, the consequences of cognitive impairment may be somehow influenced by factors such as coping or social support, which could explain why MMSE is not significantly associated with caregivers burden in other studies [13,34]. The MMSE represents only one aspect of dementia, however the most difficult aspects that caregivers endure remains the behavioral and functional disorders associated with dementia.

The present study has confirmed the influence of BPSD on caregiver burden with the shortened version of ZBI, reinforcing the powerful link between the patient behavior and the caregiver burden, regardless of the etiological diagnosis of dementia [14, 15, 35-37]. In agreement with our results, the Ryan et al. study has shown a positive correlation between BPSD and caregiver burden, assessed with a different scale (i.e., the Caregiver Burden Interview), among patients with probable $\mathrm{AD}, \mathrm{MCI}$, or healthy status, and a negative correlation between MMSE and caregiver burden among the AD patients [38]. Furthermore, in a longitudinal study of moderate to severe AD patients, Agüera-Ortiz et al. found a stronger association between behavioral alterations and caregiver burden than with functional or cognitive impairment [39].

The present study goes a step further with exploratory analyses of the different areas of BPSD on caregiver burden. Apathy/indifference, agitation/aggression, aberrant motor behavior, appetite/eating disorders, and irritability/lability are found to increase caregiver burden. The strong link between apathy and carer burden found in the present study appears particularly interesting, since this behavioral disorder does not usually appear as the most disruptive in other studies, while in reality it is the most important $[15,40,41]$. Thus, apathy should be more taken into account as a behavioral target for non pharmacological therapies [42, 43]. In a recent review, Ornstein et al. reported that agitation/aggression, depression, and sleep disturbances were the most frequent risk factors of caregiver burden increase, but this is debated [44, 45]. As apathy and depression have been found as overlapping symptoms, it may explain why only one of these symptoms, and not both of them, is found to be related with burden [46].

The present study was also carried out on detailed domains of IADL on caregiver burden. Impairment in the functional abilities to handle finances, to prepare their own food, the responsibility for own medication, the mode of transportation, and the ability to use the telephone, after adjustment for all other cofactors reflects the situations that are the most difficult to be handled by the caregiver. In particular, the impaired activities may weigh on the caregiver by increasing the time spent caring for their relatives. This observation may underlie the link between subjective and objective caregiver burden, which is suggested by the fact that subjective burden is reported as a potential predictor of objective caregiver burden [13]. Interestingly, four out of the five domains of IADL (i.e., finances, medication, transportation, and telephone) that were found to increase caregiver burden are those that have been previously found to be correlated with cognitive impairment and autonomy loss, and which are usually used in screening for dementia in the memory clinics [47].

It should be noted that BPSD and cognitive and functional impairments are also considered as risk factors for objective caregiver burden, referring to measures such as time spent with patients, or numbers and type of tasks provided by caregivers [13].

In the present study, no significant relationship was found between patients' characteristics such as age, educational level, marital status, and caregiver burden. This observation appears consistent with previous studies [29, 48]. Nevertheless in our study, gender was associated with caregiver burden, in contrast with these previous studies. Other studies have shown various results, such as Bruce et al. which showed that patients' education, age, and gender were related to caregiver burden for patients with MCI, and previous reviews have reported that such patients' characteristics are associated with caregiver burden [13, 14, 36]. These discrepancies between studies may be explained by different age structure, gender, and educational levels in the study populations.

The design of this study (retrospective and observational) did not allow an assessment of the impact of drugs on caregivers burden, but the use of drugs was included in the analysis to adjust for their potential effect. However, surprisingly, the use of anti-dementia, antipsychotics, anxiolitics, and antidepressants drugs was associated with higher burden, and only antidepressants drugs remained significant after adjustment, in particular BPSD severity. We could have expected an opposite association, in which these pharmacological therapies would be linked with a reduced caregiver burden by decreasing the behavioral troubles but the controversy still remains regarding the effect of drugs on BPSD as well as on caregiver burden [49, 50]. One can also note that the use of anti-dementia and neuroleptic drugs was studied as aggregated variables (all the active principles being grouped together) due to the small size of the groups [51]. These aggregated variables may rather reflect the severity of the 
symptoms: when patients are at advanced stage, they may receive more drugs. In particular, antipsychotics drugs are expected to be prescribed more frequently among patients with BPSD disorders. Since BPSD disorders were significant in the multivariate model, the patients using antipsychotics drugs may be those with more disorders.

\section{Limitations}

Our study has several limitations. No detailed characteristics of the caregivers were collected in the memory clinic, such as age, gender, education, and financial resources, all of which may impact the subjective burden assessment [14]. Nevertheless the caregivers' characteristics were not related to burden in previous studies [13, 15, 29, 52]. It might be expected that the caregiver burden would be higher for younger patients, which has not been ascertained in our results. The age structure of our population may be too homogeneous to allow the observation of a difference. The group sizes according to the diagnosis etiology were small, which may prevent the observation of significant differences. However the overall sample size was large, and has allowed the study to provide a detailed analysis of the different factors that compose the scales. This study is cross-sectional, thus causal links cannot be inferred. Longitudinal data will be collected to assess the impact of intervention performed among caregivers in the memory clinic, in everyday practice.

\section{Clinical implications}

This study, conducted among patients treated at a memory clinic, highlights the importance of BPSD, such as apathy, particular activities of daily life disclosing functional impairment and cognitive decline to create groups of support for caregivers, instead of etiology of the disease.

\section{Conclusion}

The identification of risk factors of caregiver burden has appeared as an important public health concern in order to provide caregivers adequate support in order to prevent, as soon as possible, any deterioration of their psychological and physical health status. More than the diagnosis itself, primary caregivers experience a higher burden due to symptoms of the patient disease, such as impairment of functional autonomy, BPSD, and cognitive severity. All cognitive impairment etiologies should then be examined on an equal basis.
We advocate that the individual actions for caregivers should not focus on the diagnosis stage or etiology of the patient disease, but rather on the symptoms of the disease they are facing.

\section{DISCLOSURE STATEMENT}

Authors' disclosures available online (http://www.jalz.com/disclosures/view.php?id=2577).

\section{REFERENCES}

[1] Neuropathology Group of the Medical Research Council Cognitive Function, Ageing Study (MRC, CFAS) (2001) Pathological correlates of the late-onset dementia in a multicentre, community-based population in England and Wales. Lancet 357, 169-175.

[2] Bradaty H (2009) Family caregivers of people with dementia. Dialogues Clin Neurosci 11, 217-228.

[3] Seeher K, Low L, Reppermund S, Brodaty H (2013) Predictors and outcomes for caregivers of people with mild cognitive impairment: A systematic literature review. Alzheimer Dement 9, 346-355.

[4] Garand L, Dew M, Eazor L, DeKosky S, Reynolds Cr (2005) Caregiving burden and psychiatric morbidity in spouses of persons with mild cognitive impairment. Int J Geriatr Psychiatry 20, 512-522.

[5] Wolf-Maier K, Cooper RS, Banegas JR, Giampaoli S, Hense HW, Joffres M, Kastarinen M, Poulter N, Primatesta P, Rodriguez-Artalejo F, Stegmayr B, Thamm M, Tuomilehto J, Vanuzzo D, Vescio F (2003) Hypertension prevalence and blood pressure levels in 6 european countries, Canada and the United States. JAMA 289, 2363-2369.

[6] Akkerman R, Ostwald S (2004) Reducing anxiety in Alzheimer's disease family caregivers: The effectiveness of nine-week cognitive-behavioral intervention. Am J Alzheimers Dis Other Demen 19, 117-123.

[7] von Kanel R, Mausbach B, Patterson T, Dimsdale J, Aschbacher K, Mills P, Ziegler M, Ancoli-Israel S, Grant I (2008) Increased Framingham Coronary Heart Disease Risk Score in dementia caregivers relative to non-caregiving controls. Gerontology 54, 131-137.

[8] Lee S, Colditz G, Berkman LF, Kawachi I (2003) Caregiving and risk of coronary heart disease in U.S. women: A prospective study. Am J Prev Med 24, 113-119.

[9] Schulz R, Beach S (1999) Caregiving as a risk factor for mortality: The Caregiver Health Effects Study. JAMA 23, 2215-2219.

[10] Schulz R, Belle S, Czaja S, McGinnis K, Stevens A, Zhang S (2004) Long-term care placement of dementia patients and caregiver health and well-being. JAMA 292, 961-967.

[11] Graff M, Adang E, Vernooij-Dassen M, Dekker J, Jonsson L, Thijsen M, Hoefnagels W, Rikkert M (2008) Community occupational therapy for older patients with dementia and their care divers: Cost effectiveness study. BMJ 336, 134-138.

[12] Callahan CM, Boustani M, Unverzagt F, Austrom M, Damush T, Perkins A, Fultz B, Hui S, Counsell S, Hendrie H (2006) Effectiveness of collaborative care for older adults with Alzheimer disease in primary care: A randomized controlled trial. JAMA 295, 2148-2157.

[13] Wolfs C, Kessels A, Severens J, Brouwer W, de Vugt M, Verhey F, Dirksen C (2012) Predictive factors of the objective 
burden in informal care in people with dementia. Alzheimer Dis Assoc Disord 2, 197-204.

[14] Torti F, Gwyther L, Reed S, Friedman J, Schulman K (2004) A multinational review of recent trends and reports in dementia caregiver burden. Alzheimer Dis Assoc Disord 2004, 99-109.

[15] Rosdinom R, Zarina M, Zanariah M, Marhani M, Suzaily W (2013) Behavioural and psychological symptoms of dementia, cognitive impairment and caregiver burden in patients with dementia. Prev Med 57, S67-S69.

[16] Zarit S, Todd P, Zarit J (1986) Subjective burden of husbands and wives as caregivers: A longitudinal study. Gerontologist 26, 260-266.

[17] Revel V, Haritchabalet I, Kervinio C, Drode M, Sauvanier M, Geny C, Placines B, Roux C, Albert D, De La Fournière F, Dartigues JF (2002) Construction d'une êchelle simplifiêe pour la dêtection en mêdecine gênêrale du fardeau de l'aidant d'une personne âgêe dêpendante. L'annêe Gêrontol 16, 131-137.

[18] Mckeith I, Cummings J (2005) Behavioural changes and psychological symptoms in dementia disorders. Lancet Neurol 4 , 735-742.

[19] Lawton MP, Brody EM (1969) Assessment of older people: Self-maintaining and instrumental activities of daily living. Gerontologist 9, 179-186.

[20] Folstein MF, Folstein SE, McHugh PR (1975) "Mini-mental state". A practical method for grading the cognitive state of patients for the clinician. J Psychiatr Res 12, 189-198.

[21] Albert MS, DeKosky ST, Dickson D, Dubois B, Feldman HH, Fox NC, Gamst A, Holtzman DM, Jagust WJ, Peterson RC, Snyder PJ, Carrillo MC, Thies B, Phelps CH (2011) The diagnosis of mild cognitive impairment due to Alzheimer's disease: Recommendations from the National Institude on Aging-Alzheimer's Association workgroups on diagnosis guidelines for Alzheimer's disease. Alzheimers Dement 7, 270-279.

[22] McKhann G, Knopman D, Chertkow H, Hyman B, Jack Cj, Kawas C, Klunk W, Koroshetz W, Manly J, Mayeux R, Mohs R, Morris J, Rossor M, Scheltens P, Carrillo M, Thies B, Weintraub S, Phelps CH (2011) The diagnosis of dementia due to Alzheimer's disease: Recommendations from the National Institute on Aging-Alzheimer's Association worgroups on diagnosis guidelines for Alzheimer's disease. Alzheimer Dement 7, 263-269.

[23] Mckeith I, Dickson D, Lowe J, Emre M, O’Brien J, Feldman HH, Cummings J, Duda JE, Lippa C, Perry E, Aarsland D, Arai H, Ballard C, Boeve B, Burn D, Costa D, Del Ser T, Dubois B, Galasko D, Gauthier S, Goetz C, Gomez-Tortosa E, Halliday G, Hansen L, Hardy J, Iwatsubo T, Kalaria R, Kaufer D, Kenny R, Korczyn A, Kosaka K, Lees A, Litvan I, Londos E, Lopez O, Minoshima S, Mizuno Y, Molina J, MukaetovaLadinska E, Pasquier F, Perry R, Schulz J, Trojanowski J, Yamada M (2005) Diagnosis and management of dementia with Lewy bodies: Third report of the DLB Consortium. Neurology 65, 1863-1872.

[24] Roman GC, Tatemichi TK, Erkinjuntti T, Cummings JL, Masdeu JC, Garcia JH, Amaducci L, Orgogozo JM, Brun A, Hofman A (1993) Vascular dementia: Diagnostic criteria for research studies. Report of the NINDS-AIREN International Workshop. Neurology 43, 250-260.

[25] Rascovsky K, Hodges JR, Knopman D, Mendez M, Kramer $\mathrm{JH}$, Neuhaus J, van Swieten JC, Seelaar H, Dopper EG, Onyike CU, Hillis AE, Josephs KA, Boeve BF, Kertesz A, Seeley WW, Rankin KP, Johnson JK, Gorno-Tempini ML, Rosen H, Prioleau-Latham CE, Lee A, Kipps CM, Lillo P, Piguet O, Rohrer JD, Rossor MN, Warren JD, Fox NC,
Galasko D, Salmon DP, Black SE, Mesulam M, Weintraub S, Dickerson BC, Diehl-Schmid J, Pasquier F, Deramecourt V, Lebert F, Pijnenburg Y, Chow TW, Grafman FM, Cappa J, Freedman SF, Grossman M, Miller M, BL (2011) Sensitivity of revised diagnostic criteria for the behavioural variant of frontotemporal dementia. Brain 134, 2456-2477.

[26] Chuma Kraemer H, Stice E, Kazdin A, Offord D, Kupfer D (2001) How do risk factors work together? Mediators, moderators, and indepedent, overlapping, and proxy risk factors. Am J Psychiatry 158, 848-856.

[27] Etters L, Goodall D, Harrison B (2008) Caregiver burden among dementia patient caregivers: A review of the litterature. J AM Acad Nurse Pract 20, 423-428.

[28] Thommenssen B, Aarsland D, Braekhus A, Oksengaard A, Engedal K, Laake K (2007) The psychosocial burden on spouses of the elderly with stroke, dementia and Parkinson's disease. Int J Geriatr Psychiatry 17, 78-84.

[29] Mohamed S, Rosenbeck R, Lyketsos C, Schneider L (2010) Caregiver burden in Alzheimer disease: Cross-sectional and longitudinal patient correlates. Am J Geriatr Psychiatry 18, 917-927.

[30] Leinonen E, Korpisammal L, Pulkkinen L, Pukuri T (2001) The comparison of burden between caregiving spouses of depressive and demented patients. Int J Geriatr Psychiatry 16, 389-393.

[31] Bêdard M, Pedlar D, Martin N, Malott O, Stones M (2000) Burden in caregivers of cognitively impaired older adults living in the community: Methological issues and determinants. Int Psychogeriatr 12, 307-332.

[32] Machnicki G, Allegri R, Dillon C, Serrano C, Taragono F (2009) Cognitive, functional and behavioral factors associated with the burden of caring for geriatric patients with cognitive impairment or depression: Evidence from a South American sample. Int J Geriatr Psychiatry 24, 383-389.

[33] Riedijk SR, De Vugt ME, Duivenvoorden HJ, Niermeijer MF, Van Swieten JC, Verhey FR, Tibben A (2006) Caregiver burden, health-related quality of life and coping in dementia caregivers: A comparison of frontotemporal dementia and Alzheimer's disease. Dement Geriatr Cogn Disord 22, 405-412.

[34] Dunkin J, C, A-H (1998) Dementia caregiver burden: A review of the literature and guidelines for assessment and intervention. Neurology 51, S53-S60.

[35] Teri L (2005) Behavior and caregiver burden: Behavioral problems in patients with Alzheimer disease and its association with caregiver distress. CNS Spectr 10, 481-488.

[36] Bruce J, McQuiggan M, Williams V, Westervelt H, Tremont G (2008) Burden among spousal and child caregivers of patients with mild cognitive impairment. Dement Geriatr Cogn Disord 25, 385-390.

[37] Lim P, Sahadevan S, Choo G, Anthony P (1999) Burden of caregiving in mild to moderate dementia: An Asian experience. Int Psychogeriatr 11, 411-420.

[38] Ryan K, Weldon A, Persad C, Heidebrink J, Barbas N, Giordani B (2012) Neuropsychiatric symptoms and executive functioning in patients with mild cognitive impairement: Relationship to cargiver burden. Dement Geriatr Cogn Disord 34, 206-215.

[39] Agüera-Ortiz L, Frank-Garcia A, Gil P, Moreno A (2010) Clinical progression of moderate-to-severe Alzheimer's disease and caregiver burden: A 12-month multicenter prospective observational study. Int Psychogeriatr 22, 12651279.

[40] Pang F, Chow T, Cummings J, Leung V, Chiu H, Lam L, Chen Q, Tai C, Chen L, Wang S, Fuh J (2002) Effect of 
neuropsychiatric symptoms of Alzheimer's disease on Chinese and American caregivers. Int J Geriatr Psychiatry 17, 29-34.

[41] Robert PH, Berr C, Volteau M, Bertogliati-Fileau C, Benoit M, Guerin O, Sarazin M, Legrain S, Dubois B (2008) Importance of lack of interest in patients with mild cognitive impairment. Am J Geriatr Psychiatry 16, 770-776.

[42] Ishii S, Weintraub N, Mervis JR (2009) Apathy: A common psychiatric syndrome in the elderly. J Am Med Dir Assoc 10, 381-393.

[43] Robert PH, Mulin E, Mallea P, David R (2010) Review: Apathy diagnosis, assessment, and treatment in Alzheimer's disease. CNS Neurosci Ther 16, 263-271.

[44] Ornstein K, Gaugler J (2012) The problem with "problem behaviors": A systematic review of the association between individual patient behavioral and psychological symptoms and caregiver depression and burden with the dementiacaregiver dyad. Int Psychogeriatr 24, 1536-1552.

[45] Ornstein K, Gaugler J, Devanand D, Scarmeas N, Zhu C, Stern Y (2013) The differential impact of unique behavioral and psychological symptoms for the dementia caregiver: How and why do patients' individual symptom clusters impact caregiver depressive symptoms? Am J Geriatr Psychiatry 21, 1277-1286.

[46] Benoit M, Berrut G, Doussaint J, Bakchine S, BoninGuillaume S, Fremont P, Gallarda T, Krolak-Salmon P, Marguet T, Mekies C, Sellal F, Schuck S, David R, Robert P (2012) Apathy and depression in mild Alzheimer's disease:
A cross-sectional study using diagnostic criteria. J Alzheimer Dis 31, 325-334.

[47] Barberger-Gateau P, Commenges D, Gagnon M, Letenneur L, Sauvel C, Dartigues JF (1992) Instrumental activities of daily living as a screening tool for cognitive impairment and dementia in elderly community dwellers. J Am Geriatr Soc 40, 1129-1134.

[48] Kim S, Kim J, Stewart R, Bae K, Yang S, Shin I, Shin H, Yoon J (2006) Correlates of caregiver burden for Korean elders according to cognitive and functional status. Int J Geriatr Psychiatry 21, 853-861.

[49] Levy K, Lanctot K, Farber S, Li A, Herrmann N (2012) Does pharmacological treatment of neuropsychiatric symptoms in Alzheimer's disease relieve caregiver burden. Drugs Aging 29, 167-169.

[50] Mohamed S, Rosenbeck R, Lyketsos C, Kaczynski R, Sultzer D, Schneider L (2012) Effect of second-generation antipsychotics on caregiver burden in Alzheimer's disease. J Clin Psychiatry 73, 121-128.

[51] Black S, Doody R, Li H, McRae T, Jambor K, Xu Y, Sun Y, Perdomo C, Richardson S (2007) Donezepil preserves cognition and global function in patients with severe Alzheimer disease. Neurology 69, 459-469.

[52] Annersted L, Elmstahl S, Ingvad B, Samuelsson S (2000) Family careviging in dementia - an analysis of the caregiver's burden and the "breaking-point" when home care becomes inadequate. Scand J Public Health 28, 23-31. 